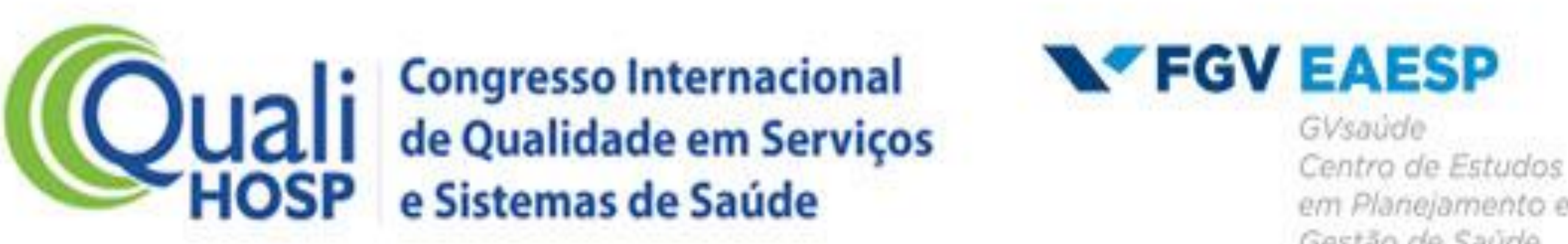

Erica Tavares Belli, Patrícia do Prado Costa Braga, Roseli Gomes Cavalini, Sheila Pereira Mendes, Silvia Evangelista dos Santos

\section{RELATO DE EXPERIENCIA: ATUAÇÃO DA EQUIPE DE ENFERMAGEM NA GESTÃO DO TEMPO NO GERENCIAMENTO DE RECURSOS MATERIAIS EM UMA UNIDADE DE INTERNAÇÃO CIRURGICA.}

Eixo temático: Gestão em Saúde

INTRODUÇÃO: Uma das atribuições do enfermeiro é administrar materiais, definida como a atividade de planejar, executar e controlar, nas condições mais eficientes e econômicas, o fluxo de material, partindo das especificações dos artigos a comprar até a entrega e utilização do produto. Nas instituições de saúde, cujo produto final é a prestação da assistência aos clientes através de ações terapêuticas que não podem sofrer interrupções.

JUSTIFICATIVA: O desperdício ocorre, muitas vezes, não por uma má administração, mas por falta de uma percepção mais eficiente por parte dos colaboradores por este motivo realizamos - levantamento do tempo que o colaborador leva para buscar materiais na farmácia em uma unidade de internação, sabemos que a gestão do tempo e de grande importância na gestão do cuidado.

OBJETIVO: Reduzir o tempo desprendido da enfermagem desnecessariamente nas idas a farmácia para solicitação de requisição de materiais.
RESULTADOS: Realizou-se um levantamento do consumo de materiais utilizados nas 24 horas gerando uma lista com a quantidade dos materiais utilizados na unidade, conforme o uso, os materiais são repostos no final de cada plantão. Observou-se que a enfermagem levava muito tempo nas idas a farmácia em média de 20 minutos, em 12 horas o colaborador ia até 8 vezes na farmácia,com a reestruturação da solicitação de materiais esse tempo ficou despendido para a assistência direta ao paciente, pois não há mais necessidade de idas a farmácia.

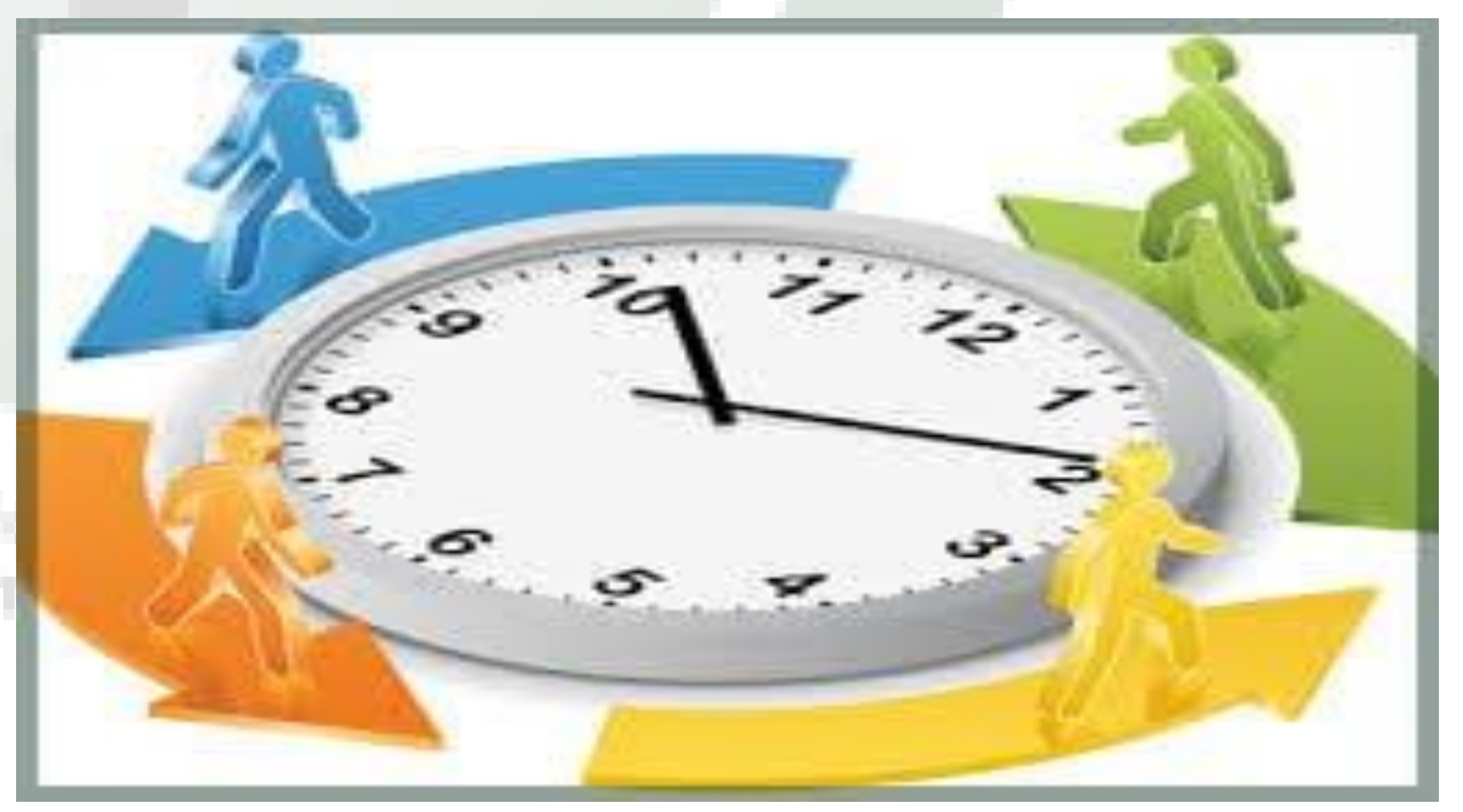

CONCLUSÃO: Percebemos uma melhora do tempo da enfermagem, uma vez que se dispensava muito tempo em busca dos materiais para a assistência ao paciente. 